\title{
Continuous production of multicomponent powder mixtures
}

\author{
Wasem Mansour ${ }^{1}$, Denis Melekhin ${ }^{2}$, and Alexander Pasko ${ }^{3 *}$ \\ ${ }^{1}$ Post-graduate student from the Syrian Arab Republic, Tambov State Technical University, 106 \\ Sovetskaya Street, 392000, Tambov, Russian Federation \\ ${ }^{2}$ Architecture Faculty, Czech Technical University in Prague, 1903/4 Zikova, 16636 Prague 6 Czech \\ Republic \\ ${ }^{3}$ Department of Technology and Methods of Nanoproducts Manufacturing, Tambov State Technical \\ University, 106 Sovetskaya Street, 392000, Tambov, Russian Federation
}

\begin{abstract}
Mixing of powders is an important process in various industries, from chemical, pharmaceutical to food and construction. The main characteristic of the mixture is its homogeneity, which is usually estimated by the coefficient variation and the lower this ratio, the better the mixture. Typically, particles of the components of the mixture differ in size and / or density. These differences cause segregation, i.e. the formation of zones in which there is a high concentration of one of the components and this affects the quality of the mixture. However, through the use of special technological methods, the negative result of segregation can be transformed into a positive one and not only reduce the mixing time, but also improve the quality of the mixture. This article discusses one of the options for the production of a multicomponent mixture with a specific schedule for loading components. It is shown that by organizing the correct sequence of loading components, you can control the mixing process. Two-step technology is used to feed components into the mixer.
\end{abstract}

\section{Introduction}

Mixing of powders is an important process in various industries, from chemical, pharmaceutical to food and construction. The main characteristic of the mixture is its homogeneity, which is usually estimated by the variation of the coefficient. The greater the coefficient of heterogeneity, the worse the quality of the mixture. In addition, when implementing mixing processes, it is necessary to minimize the process time and energy consumption to a minimum. Often the mixing process is complicated by the presence of liquid components, which requires other technologies and mixer designs. For example, in the production of concrete, graphene structures are introduced in the form of an aqueous suspension [1]. A similar situation arises when modifying epoxy resin [2] or lubricants with graphene nanostructures [3-5]. Sometimes the mixing process directly determines the quality of the finished product.

*Correspondingauthor:ttmp2005@yandex.ru 
Carbon black is an important component of the electrodes of lithium-ion batteries, as it significantly improves the electrical conductivity in the coating. It is shown in the paper [6] that the structure of soot in the electrodes of a lithium-ion battery can be precisely controlled by careful changes in parameters in the upward dry mixing process. Significant changes in important properties of electrodes, such as mechanical, structural and electrical characteristics are achieved and can be described as functions of the process parameters "Mixing time" and "mixing intensity". Thus, the proper organization of the mixing process can improve the performance of the finished product.

In addition to the large difference in the percentage of individual components in the mixture, often there is a large difference in the particle sizes of the various components. For example, in the production of a multicomponent powder mixture $\mathrm{Fe}-\mathrm{Cr}-\mathrm{Co}-\mathrm{Ni}-\mathrm{Mn}[7]$, the following materials were used as starting components: radio engineering carbonyl iron powder (R-10 with an average particle size $d=3.5 \mu \mathrm{m})$, nickel powder (NPE-1, $\mathrm{d}=150$ $\mu \mathrm{m})$, cobalt powder $(\mathrm{PK}-1 \mathrm{u}, \mathrm{d}<71 \mu \mathrm{m})$, chromium powder $(\mathrm{PH}-1 \mathrm{M}, \mathrm{d}<125 \mu \mathrm{m})$ and manganese powder (MR0, $\mathrm{d}<400 \mu \mathrm{m}$ ). In this case, the particle size differs by more than 100 times. Such a difference in size causes active segregation of these components in the mixer, i.e. particles with a maximum size are concentrated in one zone of the mixer, and particles with a minimum size in another zone of the mixer and this greatly reduces the quality of the finished mixture. To solve the problem of separation of the prepared mixture, the mixing process was carried out in an AGO-2 mechanical activator with water cooling, using steel balls with a diameter of $9 \mathrm{~mm}$ and acceleration in air of $90 \mathrm{~g}$. The best results were obtained with a mixing (alloying) time of 90 minutes.

Majority of the active ingredients and adjuvant used for the manufacture of pharmaceutical dosage forms constitutes in the powder form, the market for solid dosage forms involving powder processing is large and is growing day by day [8]. Handling and processing of powders, in particular feeding and mixing is central to pharmaceutical operations. But it poses numerous problems due to their unpredictable and irregular behavior. The article deals with sequential approaches to be enforced by the pharmaceutical industries to draw out new technical responses to change with respect to mixing.

Scientists and engineers are constantly creating new mixer designs. For example, based on an analysis of methods for mixing bulk materials and mixer designs, the method of continuous mixing of bulk materials and the design of a spiral mixer are justified [9]. The main idea is that a multilayer component stream is formed in the desired ratio, followed by dividing the stream into small portions and mixing the components into portions. In our opinion, the authors of this work did not pay enough attention to the dosing accuracy of the component, but if there is no exact ratio of the components, it is impossible to prepare a good mixture. By the way, when modeling the mixing process, the dosing errors of the components are also not taken into account.

In recent decades, for the production of new structural and functional materials, not only micro, but also nanoscale components have been used. For example, in the manufacture of catalysts for the production of gasoline, a mixture of iron and platinum particles with sizes less than 100 nanometers is used.

In this article, we analyze the possibility of preparing multicomponent mixtures with a specific schedule for loading components using two-step feeding technology.

\section{Multi-component mixing technology}

Actually, the components of the mixture have a difference in size and/or density, which causes particle segregation. The result of segregation is the formation of several zones, in each of which one of the components prevails. Small differences in either size or density lead to flow-induced segregation, a complex phenomenon without parallel in fluids [10].It 
is believed that segregation negatively affects the mixing process, however, in some cases; the effect of segregation can be used to intensify the mixing process and improve the quality of the finished mixture. An analysis of articles on mixing bulk materials [10-16] shows that, regardless of the type of mixer, the process of mixing particles has a deterministic-stochastic nature. At the same time, depending on the type of mixer, either the deterministic component or the stochastic component prevails.Obviously, the deterministic mixing process is easier to control than the stochastic mixing process. A striking representative of mixers in which deterministic particle motion can be observed, and therefore deterministic mixing, is a drum mixer, i.e. horizontal rotating cylinder, inside which a mixture of different particles moves. It is best when the bulk material moves in a rolling / cascading mode. In this case, the particles move in a closed loop. Part of the particles that are closer to the drum rise up, and the other part of the particles rolls down. Numerous experimental studies show that if the particles of the two components differ in particle size or density, then regardless of how to initially load these particles into the drum, as a result of the rotation of the drum, small or heavy particles form a region in the centre of the circulation circuit, i.e. particle segregation will occur.

In order to convert the negative effect of the segregation effect into a positive one, a specific procedure for loading components into a batch mixer is proposed [17-19]. The idea is very simple and understandable, it is necessary to load the particles of a specific component into a zone that is diametrically opposite to that zone to which this component will be located as a result of a long rotation of the drum. Let us consider the schedule for loading components into a continuous drum mixer. Suppose that we need to prepare a mixture of three components $\mathrm{A}, \mathrm{B}$ and $\mathrm{C}$, and the particles of these components have different diameters; LJJ.Figure 1 shows a diagram of the loading of components into a drum mixer and a number of cross-sections of the mixer, which show the characteristic distribution of the components.

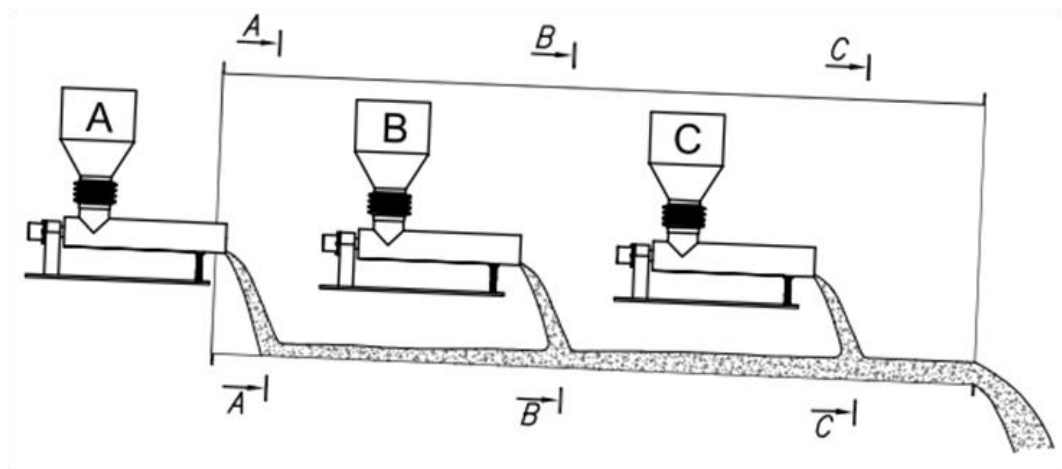

a)

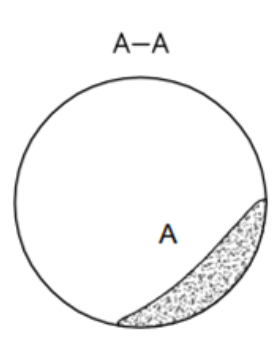

b)

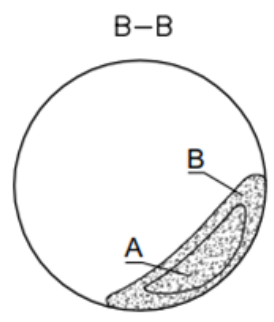

c)

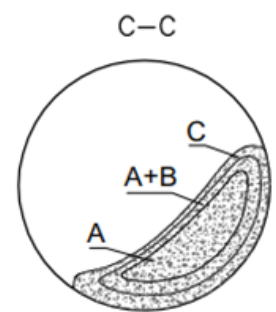

d)

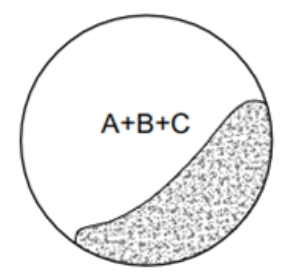

e)

Fig. 1.Scheme of loading components into a drum mixer. 
The loading of components into the mixer is as follows. First of all, component A is loaded, since it has the largest particles. The rotation speed of the drum is selected so that there is a circulation mode of movement of the bulk material, as shown in figure 1b. Then there is a continuous loading of component $\mathrm{B}$, as shown in figure $1 \mathrm{c}$. Component $\mathrm{B}$ is distributed evenly along the external boundary of the circulation circuit and the process of mixing components $\mathrm{A}$ and $\mathrm{B}$ begins. After that, component $\mathrm{C}$ is continuously loaded, which is initially evenly distributed at the external boundary of the circulation circuit. As noted above, since the particle size of component B is smaller than the particle size of component $\mathrm{A}$, these particles will move toward the center of the circulation circuit. By the time component $\mathrm{C}$ is loaded, partial mixing of components $\mathrm{A}$ and $\mathrm{B}$ will occur, as shown in Figure 1e. Since the particles of component $C$ are the smallest size, they will begin to move toward the center of circulation. At the outlet of the mixer, a mixture is formed in which components A, B and C are evenly distributed. The components are loaded similarly if they differ in density. First you need to load the lightest component, and then a heavier one and lastly you need to load the heaviest component. This is a general strategy for loading components, but the location of the dispensers of components $\mathrm{A}, \mathrm{B}$ and $\mathrm{C}$ along the axis of the drum depends on the ratio of the diameters and/or densities of these components, as well as the percentage of components in the mixture.

The most difficult problem is solved when the particles of the components differ not only in particle sizes [20,21], but in the densities of the materials of these particles, and large particles are also the heaviest. Unfortunately, in the scientific literature, we did not find reliable dependences for determining the tendency of particles to segregate while simultaneously differing in the diameters of these particles and in the densities. So far, the only reliable option is to conduct research on a laboratory drum in a batch mode.

\section{Experiment, Results, and Discussion}

We conducted experimental studies on a laboratory drum with a diameter of $400 \mathrm{~mm}$ and a length of $50 \mathrm{~mm}$, since it was previously shown that the continuous mixing process in a drum mixer can always be adequately implemented in a batch mixer. Indeed, the movement of bulk material along the axis of a drum that operates in continuous motion is the movement of material at different points in time in a drum that operates in a batch mode. The main condition is to determine the degree of filling the material with material, since this degree decreases from the beginning of the drum to the discharge edge. This problem was solved analytically and experimentally verified $[22,23]$.

This setup consisted of a drum with a transparent front end wall so that it was possible to observe the movement of the material and the distribution of components in the volume of the mixture. The components were fed into the drum by a device that implemented a two-stage dosing technology. The essence of this technology is that at the first stage, the batch dispenser forms separate batches of material with a given weight and at regular intervals feeds these batches into a cylindrical tray, which performs circular oscillations. At the second stage, under the influence of vibration, individual portions are converted into a continuous stream and enter a rotating drum. This design allows you to accurately simulate the operation of a continuous mixer.

First of all, we checked the initial hypothesis: regardless of the component loading, small or heavy particles are collected in the centre of the circulation circuit. Figure $2 \mathrm{a}$ shows the loading of millet in the outer zone of the circulation circuit, which was formed by particles of polyethylene in the cross section of a rotating drum. Figure $2 b$ shows the distribution of components after 3 minutes of rotation of the drum. Despite the fact that the zone in which the millet particles were concentrated is not pronounced, it is seen that most of the millet particles are located near the centre of circulation. 


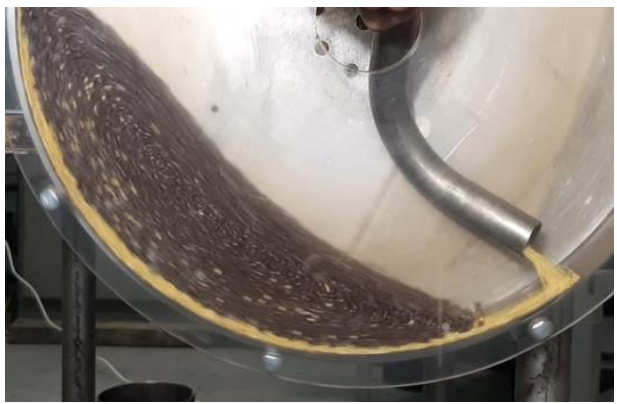

a)

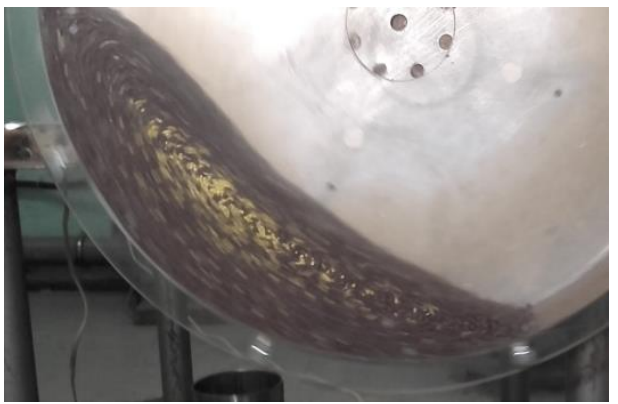

b)

Fig. 2.Distribution of the key component in a rotating drum: $a$ - immediately after loading; $b-3$ minutes after loading.

In real experiments, we used a transparent end wall with a large number of holes. These openings were covered with lids, but they were opened for sampling. Through these holes, samples of the mixture were taken and the number of individual components in each sample was determined. The quality of the mixture was evaluated by the coefficient of variation, which for mixtures is usually called the coefficient of heterogeneity:

$$
k_{c}=\frac{100}{\bar{c}} \sqrt{\frac{1}{n-1} \sum\left(c_{i}-\bar{c}\right)^{2}}
$$

where $k_{c}$ is the heterogeneity coefficient, $\% ; \bar{c}$ is the average concentration of the key component in the sample; $c_{i}$ concentration in $i$ sample; $\mathrm{n}$ is the number of analyzed samples.

As you know, the lower the coefficient of variationis, the better the mixture is, i.e. the more uniformly all components are distributed throughout the volume of the mixture.

As components, we used materials with different particle sizes and different colors, which facilitated the determination of the concentration of individual components in the samples. For example, we used: component A - polyethylene granules with a particle diameter of $1.5 \mathrm{~mm}$ to $3 \mathrm{~mm}$ (black); component $\mathrm{B}$ - millet with a particle diameter of 1 $\mathrm{mm}$ (yellow); table salt with a particle diameter of $0.5 \mathrm{~mm}$ (white). In addition, we used river sand of various sizes. The concentration of any fraction was easily determined using a sieve analysis.

As an example, figure 3 shows the variation of the coefficients of variation for mixtures $\mathrm{A}+\mathrm{B}$ and $\mathrm{A}+\mathrm{C}$. All components are sand. The particle size of component $\mathrm{A}$ is from 0.15 to $0.20 \mathrm{~mm}$, component $\mathrm{B}$ is from 0.08 to $0.09 \mathrm{~mm}$, and component $\mathrm{C}$ is from 0.04 to 0.045 $\mathrm{mm}$.

As you can see the minimum value of the coefficient of variation for the mixture $\mathrm{A}+\mathrm{C}$ occurs faster than for the mixture $\mathrm{A}+\mathrm{B}$. This is because the difference in particle sizes of components $\mathrm{A}$ and $\mathrm{C}$ is two times larger, the difference in particle sizes of components $\mathrm{A}$ and $\mathrm{B}$. It should be noted that after reaching the minimum value of the coefficient of variation, it begins to increase and the quality of the mixture becomes worse. In the final result, there will be almost complete separation of the components in the sub-zones, as shown in figure $2 b$. The change in the coefficient of variation for the mixture $B+C$ is not shown, because the dependence is fully consistent with the mixture $\mathrm{A}+\mathrm{B}$.

The figure 4 shows the change in the coefficient of variation for the mixture $A+B+C$. 


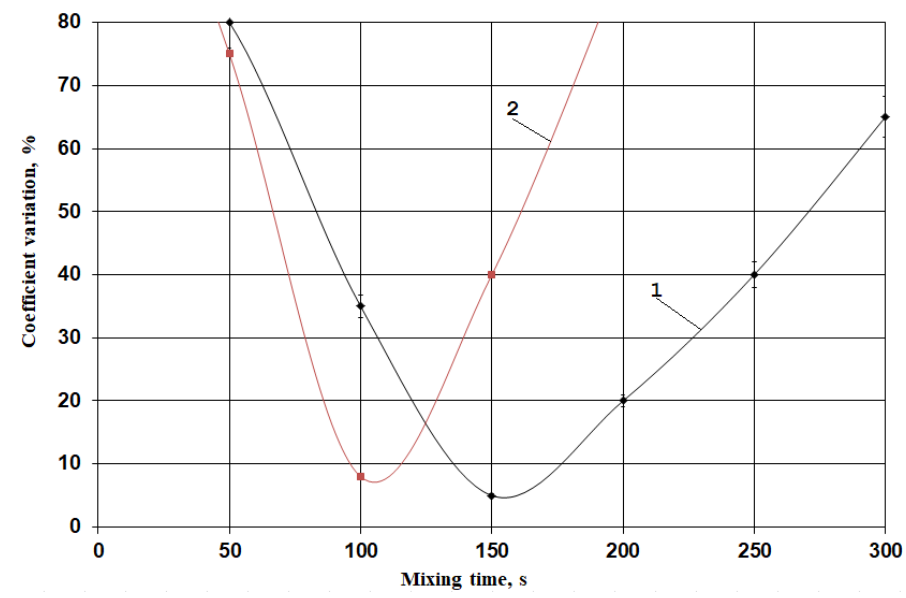

Fig. 3. Change in the coefficient of variation over time: 1 - a mixture of components A and B; 2 - a mixture of components $\mathrm{A}$ and $\mathrm{C}$.

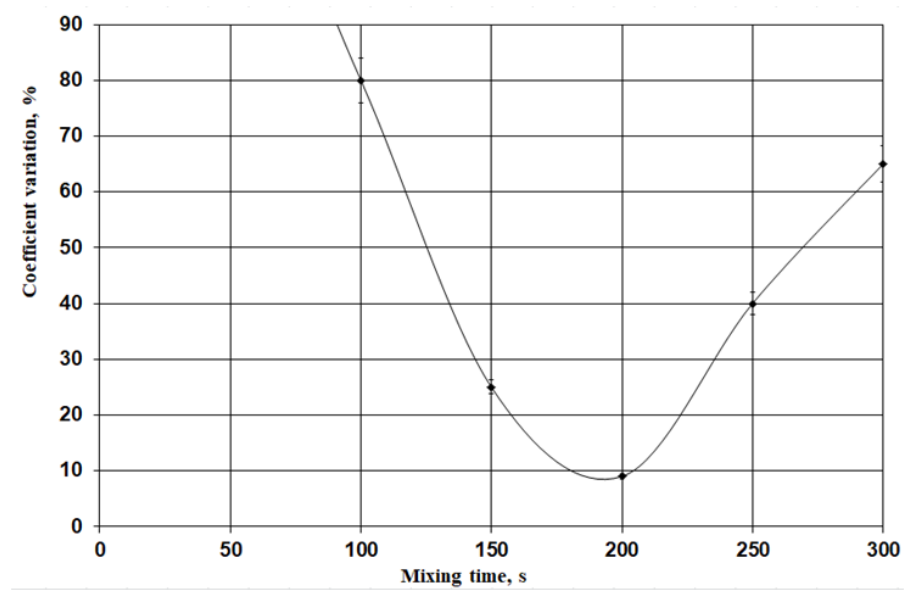

Fig. 4. Change in the coefficient of variation over time of a mixture of components A, B and C.

By nature, the curve shown in figure 4 is similar to the curves shown in figure 3 . The curves differ in the minimum values of the coefficient of variation and the time in which these minimum values are reached. From a practical point of view, it should be noted that these two values depend only on the ratio of the sizes of the components and their percentage in the mixture, but also on the intensity of the supply of these components to the mixer.

The graphs show that the coefficient of variation decreases first (the components are evenly distributed over the entire volume of the mixture) and then increases (small particles gather near the center of circulation. The larger the difference between the particle sizes is, the faster the process goes. You can see that when mixing components A and B (particles B are approximately 2 times smaller than particles A), the minimum coefficient of variation is achieved in more than $150 \mathrm{~s}$, and when components $\mathrm{A}$ and $\mathrm{C}$ are mixed (particles $\mathrm{C}$ are approximately 4 times smaller than particles $\mathrm{A}$ ), the minimum coefficient of variation is attained in less than $100 \mathrm{c}$. A similar conclusion can be drawn regarding the segregation rate. The mixture of components $\mathrm{A}$ and $\mathrm{B}$ almost completely segregate approximately $400 \mathrm{c}$, and a mixture of components $\mathrm{A}$ and $\mathrm{C}$ is segregated in approximately $250 \mathrm{~s}$. 
It should be especially noted that in the production of multicomponent mixtures it is very important that the components are accurately feeding. Currently, the most commonly used feeders, which implement the "Weight Loss" technology. Despite the claims made by the manufacturers of these feeders that they have very high metering accuracy, this is not so. The reason is that the weighing of the material is carried out in motion and dynamic effects on the weight sensor reduces the accuracy of feeding.

Figure 4 shows the change in the coefficient of variation in the mixture of components $\mathrm{A}, \mathrm{B}$ and $\mathrm{C}$. In this case, the concentration of component $\mathrm{B}$ was $10 \%$, and component $\mathrm{C}$ $5 \%$. We evaluated the quality of the mixture by the coefficient of variation of component $\mathrm{C}$. The components were loaded according to the scheme shown in Figure 1a.

For continuous feeding of components, as noted above, we used the technology of twostep feeding [24-27]. This technology has been studied in sufficient detail, but for the organization of the continuous production of multicomponent mixtures, additional theoretical and experimental studies are needed. Despite the fact that there are dependencies for determining the parameters of material motion [28-31] and various models of the process of mixing bulk materials [32-36], including in a rotating drum [37-40], these questions require further theoretical and experimental studies. Particular attention should be paid to the relationship of component dispensers and a drum mixer in order to make the best possible industrial use of the technology proposed in this paper.

\section{Conclusion}

The negative effect of segregation can and should be used to reduce the mixing time of components that differ in particle size and / or density, as well as to improve the quality of the finished mixture. The main condition is the correct loading of the components in the mixer. Particular attention should be paid to the accuracy of continuous dispensing of components and the placement of dispensers along the length of the mixer. In addition, to calculate the parameters of industrial plants, it is necessary to develop mathematical models of joint processes for the continuous supply of components and their mixing in a continuous mode.

\section{References}

1. V. Pershin, K.A. Al-Shiblawi, A.M.R. Al-Mashhadani, A. Pasko, D. Melekhin, IOP Conf. Ser.-Mat.Sci.693(1), 012046 (2019)

2. K.A. Al-Shiblawi, V.F. Pershin, V.P. Jarcev, T.V. Pasko, AIP Conf. Proc.2041, 020015 (2018)

3. V. Pershin, G. Zhumagalieva, A. Tkachev, A. Pasko, N. Memetov, AIP Conf. Proc.2101, 020011 (2019)

4. V. Pershin, K. Ovchinnikov, Z. Al-Hilo, N. Memetov, A. Tkachev, E. Galunin, AIP Conf. Proc.2041, 020016 (2018)

5. V.F. Pershin, K.A. Ovchinnikov, A.A. Alsilo, R.A. Stolyarov, N.R. Memetov, Nanotechnol. Russ.13(5-6), 344-348 (2018)

6. H.Bockholt, W.Haselrieder, A.Kwade, Powder Technol.297,266-274 (2016)

7. N.A. Kochetova, A.S. Rogacheva, A.S. Shchukina, S.G. Vadchenkova. I.D. Kovaleva, Russ. J. Non-Ferr. Met.+,60(3), 268-273 (2019)

8. R.Deveswaran, S.Bharath, B.V.Basavaraj, S. Abraham, S. Furtado, V.Madhavan, Research J. Pharm. and Tech.2(2), 245-249 (2009) 
9. I. Dudarev, R. Kirchuk, Y.Hunko, S.Panasyuk,Modeling of Mixing Bulk Materials, in Proceedings of the 2nd International Conference on Design, Simulation,

Manufacturing: The Innovation Exchange, DSMIE-2019, 11-14 June 2019, Lutsk, Ukraine (2019)

10. J.M. Ottino, D.V. Khakhar,Annu. Rev. Fluid Mech. 32, 55-91 (2000)

11. O.V. Dyomin, V.F.Pershin, D.O.Smolin, Chem. Petrol. Eng.+,48(3-4), 213-216 (2012)

12. V.F. Pershin, Yu.T.Selivanov, Theor. Found. Chem. Eng.37(6), 629-636 (2003)

13. V.F. Pershin, Theor. Found. Chem. Eng. 23(3), 249-255 (1990)

14. Yu.T. Selivanov, V.F.Pershin, Chem. Petrol. Eng.+,2, 7-10 (2004)

15. Yu. Selivanov, V.F.Pershin, Theor. Found. Chem. Eng. 38(1), 99-101 (2004)

16. Yu. Selivanov, V.F. Pershin, Theor. Found. Chem. Eng.38(1), 103-105(2004)

17. V.F. Pershin, Theor. Found. Chem. Eng.38(1-2), 53-57 (2002)

18. V.F. Pershin, Yu.T.Selivanov, A.V.Orlov, Chem. Petrol. Eng.+,39(1-2), 60-65 (2003)

19. V.F. Pershin, Yu.T. Selivanov, Chem. Petrol. Eng.+,40(1-2), 77-82 (2004)

20. V.F. Pershin, Yu.T. Selivanov, Theor. Found. Chem. Eng. 35(2), 206-208 (2001)

21. V.F. Pershin, Yu.T. Selivanov, Theor. Found. Chem. Eng.35(1), 86-89 (2001)

22. Yu.T. Selivanov, V.F. Pershin, Chem. Petrol. Eng.+, 2, 7-10 (2004)

23. V.F. Pershin, Yu.T. Selivanov, Theor. Found. Chem. Eng.37(6), pp. 629-636 (2003)

24. T. Alsayad, V.Pershin, A.Pasko, T. Pasko, AIP Conf. Proc.1899,060011 (2017)

25. V.F. Pershin, A.M.Vorob'ev, V.M.Nechaev, A.A.Pas'ko, T.K.K.Alsaiyad, Chem. Petrol. Eng.+, 54(5-6), 386-391 (2018)

26. N.A. Alsayyad, V.Pershin, A.Pasko, T.Pasko, J.Phys.Conf. Ser.1084(1), 012005 (2018)

27. T. Al-Sayyad, V.Pershin, A.Vorobiev, E.Galunin, AIP Conf. Proc.2041,020001 (2018)

28. V.F. Pershin, Chem. Petrol. Eng.+,22(11), 606-608 (1986)

29. V.F. Pershin, Chem. Petrol. Eng.+,24(6), 261-264 (1988)

30. V.F. Pershin, Theor. Found. Chem. Eng.22(2), 196-201 (1988)

31. V.F. Pershin, G.A.Minaev, Theor. Found. Chem. Eng.23(5), 432-435 (1990)

32. R. Liu, Z. Zhou, R. Xiao, A. Yu, Powder Technol.361, 315-325 (2020)

33. R.Cai, Z.Hou, Y. Zhao, Powder Technol. 352, 193-208(2019)

34. F.Göbel, S.Golshan, H.R.Norouzi, R.Zarghami, N.Mostoufi, Powder Technol. 346, 171-179 (2019)

35. M.Kashif, S. Muhammad, S.Siraj, Powder Technol.344, 617-627 (2019)

36. H. Fan, D.Guo, J. Dong, X. Cui, M. Zhang, Z. Zhang, Powder Technol. 327, 223-231 (2018)

37. V.F. Pershin, Theor. Found. Chem. Eng.20(4), 324-329 (1986)

38. V.F. Pershin, Yu.T.Selivanov, Theor. Found. Chem. Eng. 37(6), 629-636 (2003)

39. V.F. Pershin, Yu.T.Selivanov, A.V.Orlov, Theor. Found. Chem. Eng.38(2), 209-215 (2004)

40. V.F. Pershin, Theor. Found. Chem. Eng. 23(3), 249-255 (1990) 